\title{
Stress Fracture of the Femoral Neck in Patient With Excessive Acetabular Anteversion and Coxa Profunda: A Case Report
}

\author{
Yong-Sik Kimª, Youn-Jun Kim ${ }^{\mathrm{b}}$, Suk-Ku Han ${ }^{\mathrm{b}, \mathrm{c}}$
}

\begin{abstract}
The underlying pathomechanisms of stress fracture of the femoral neck remains unclear. Repeated or vigorous exercise or insufficient bone strength was known to be a causing factor. Recently, femoroacetabular impingement (FAI) by abnormal contact between acetabular rim and femoral head-neck is possibly known to cause a stress fracture of femoral neck. We experienced a rare case of stress fracture of femoral neck in 59-year-old patient with increased acetabular anteversion and coxa profunda. Focal or general over-coverage of femoral head by acetabulum which might evoke repeated collision between acetabulum and femoral neck caused stress fracture of femoral neck.
\end{abstract}

Keywords: Femoral neck sress fracture; Femoroacetabular impingement

\section{Introduction}

The cause of stress fracture of femoral neck is thought to be multifactorial. Repetitive vigorous activity, abnormal quality of bone or morphologic abnormalities involving proximal femur such as coxa vara are known to be related with the development of femoral neck stress fracture [1-3]. Femoroacetabular impingement is a pathologic condition in which subtle structural abnormalities of proximal femur or acetabulum can evoke an abutement between femoral neck and ac-

\footnotetext{
Manuscript accepted for publication May 10, 2013

a Department of Orthopaedic Surgery, Seoul St. Mary's Hospital, College of Medicine, The Catholic University of Korea, Seoul, Korea

${ }^{b}$ Department of Orthopaedic Surgery, St. Paul's Hospital, College of

Medicine, The Catholic University of Korea, Seoul, Korea

${ }^{\mathrm{c} C}$ Corresponding author: Suk-Ku Han, Department of Orthopaedic Surgery, St. Paul's Hospital, College of Medicine, The Catholic

University of Korea, Seoul, 180 Wangsan-ro, Dongdaemun-gu, Seoul,

Korea. Email: hnsukku@catholic.ac.kr
}

doi: http://dx.doi.org/10.4021/jmc1236w etabular edge. It is considered as a main pathophysiology to understand osteoarthritis of hip. However, a study about high prevalence of radiologic finding of acetabular retroversion, a form of femoroacetabular impingement in patients with stress fracture in military recruits had reported [4]. We propose a possible relationship between the stress fracture of femoral neck and femoroacetabular impingement in case report of patient who had the stress fracture with hip of excessive acetabular anteversion and coxa profunda.

\section{Case Report}

The patient was a 59-year-old female housewife visited hospital with a chief complaint of worsening left lateral and groin pain which was aggravated by activity and insidious in nature. She could not walk with weight bearing due to left hip pain. Over the past 3 years, she had developed stiffness and discomfort in the left hip, and over the past 2 months the hip pain had gone worse. Her usual level of activity was not different from other housewives. She had a history of hypertension, L5 spondylolysis and degenerative knee arthritis, but had no history of smoking or drinking. The body mass index indicated that she was obese (body mass index $38.2 \mathrm{~kg} / \mathrm{m}^{2}$ ). Physical examination revealed that the patient's left hip pain was primarily reproduced with passive hip flexion- adduction- internal rotation and the Patrick test. Slight weakness of the left hip abductor and internal/external rotator muscles was noted. On radiographics, a crack with lateral opening was found in left femoral neck (Fig. 1). Also, dense sclerotic line was noted around the fracture site in femoral neck. The neck-shaft angle was 128 in degree and posterior wall sign was positive. The lateral center-edge angle was 39 in degree and cross-over sign was negative. The femoral head was more medial with acetabular fossa being medial to ilioischial line (coxa profunda). Computer tomography revealed findings consistent with a complete stress fracture of subcapital neck in left hip (Fig. 2A). The irregularity of posterior articular cartilage in head, ossified labral cartilage and joint space narrowing were noted (Fig. 2B). The angle of acetabular anteversion in left hip was 29 in degree. 3D reconstructed computer tomography showed femoral head 


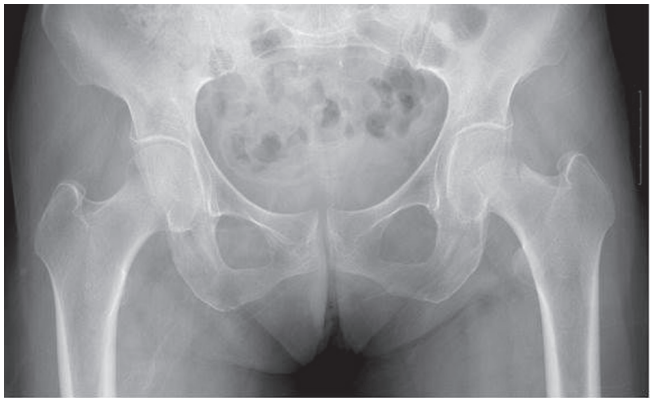

Figure 1. Radiograph shows left femoral neck fracture with coxa profunda in 59-year-old female.

was deeply located in acetabulum. Bone cysts were found in bilateral superolateral head. Also the film showed femoral head was over-covered posteriorly due to excessive acetabular anteversion (Fig. 3). Her bone mineral density in dual energy absorptiometry showed -2.1 of T-score in right femoral neck. The patient underwent total hip replacement of the left hip (Fig. 4) and successfully returned her life.

\section{Discussion}

Stress fractures of femoral neck is rare and have been known to occur possibly by repetitive cumulative load transmission across the femoral neck in highly active individuals such as athletics or military recruits and sometimes independent of
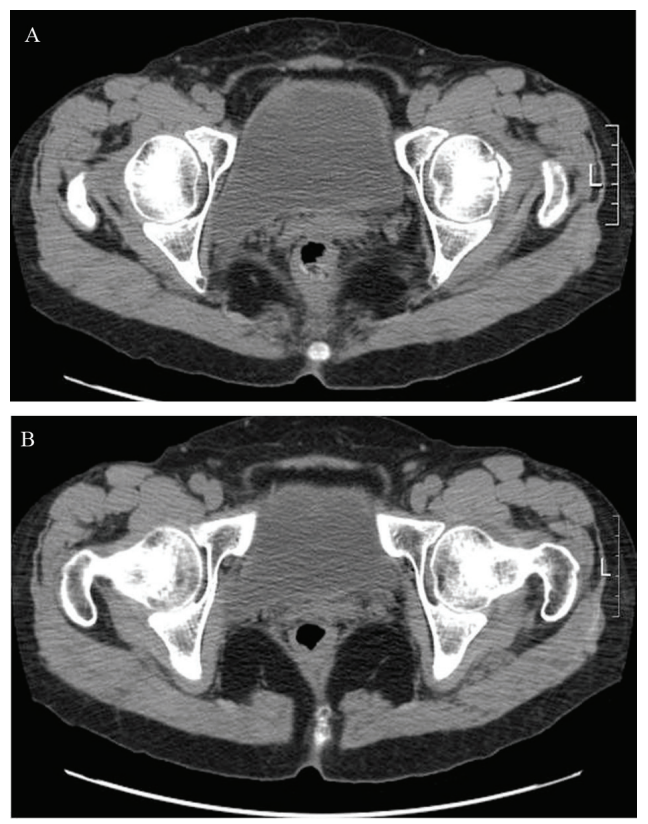

Figure 2. Computer tomogram shows complete stress fracture of femoral neck with surrounding sclerosis (A). Acetabular anteversion is increased and irregular articular surface with narrowing of joint space is seen (B).

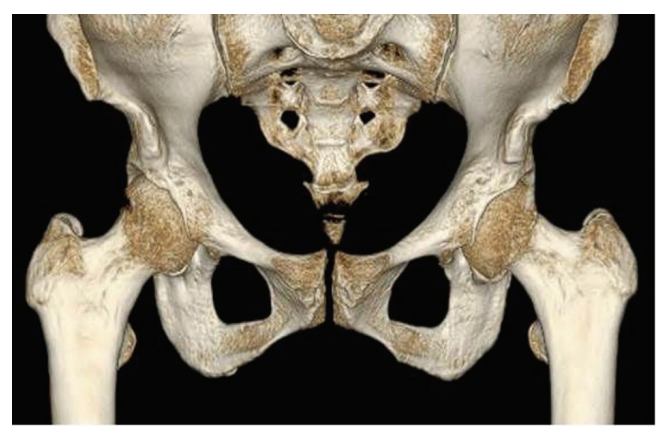

Figure 3. 3D CT shows posterior over-coverage of femoral head by acetabulum and bilateral bone cysts on superolateral head.

age in association with a range of different conditions characterized by abnormal bone-mineral content or abnormal elasticity of bone [2, 3]. Genetic factors may play a role in the development of stress fractures in individuals subjected to heavy exercise and mechanical loading [5]. Also stress fracture of the femoral neck in active adults is known to be related with coxa vara [1]. Biomechanically, direct muscle pulling effect increases in coxa vara and leads to fatigue of opposing muscle group. Recently, the paper about femoral neck stress fracture which is related with FAI was published [4].

FAI is associated with subtle morphologic abnormalities around the hip which result in abnormal contact between the femoral head/neck and the acetabular margin during extreme range of motion, causing tearing of the labrum and avulsion of the underlying cartilage lesion, continued deterioration, and eventual onset of arthritis [6, 7]. Protruded head-neck junction (cam type) and over-coverage of head by acetabulum (pincer type) or both (mixed type) evoke impingement between head and acetabulum. Cam lesion can be seen in prior femoral neck fracture, slipped capital femoral epiphysis, Legg-Calve-Perthes disease and after femoral osteotomy. Typical conditions of pincer lesion seen to cause of FAI

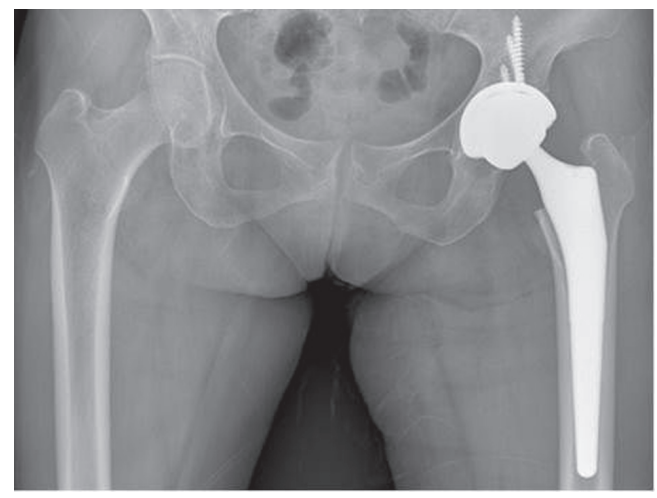

Figure 4. Ceramic-on-ceramic articulated total hip arthroplasty was performed. 
include posttraumatic deformities, coxa profunda, protrusio acetabuli, and acetabular retroversion [7].

Ganz et al. [8] first reported the association between the development of femoroacetabular impingement and femoral neck fracture. Malunited femoral neck fracture by improper reduction might produce mechanical symptoms by impingement. They found impingement phenomenon intraoperatively in cases of treatment for hip pain after femoral neck fracture. Also FAI mechanism is proposed as a cause for nonunion of femoral neck fractures [9]. Impingement was identified at surgery and all cases of nonunion went on to uneventful healing after elimination of the cause for impingement. Decreased clearance between femoral neck and acetabulum can be aggravated by a bulge or a spur at the fracture site. The acetabular rim acts as a fulcrum on which the femoral neck fracture is strained repetitively with motion across the fracture. And higher incidence of acetabular retroversion, a form of pincer type impingement, is found in military recruits with femoral neck stress fractures than the normal people [4]. But nevertheless the association between acetabular retroversion and femoral neck stress fracture, it is unclear whether the presence of acetabular retroversion is a true risk factor for development of a femoral neck stress fracture.

We report a case of stress fracture of femoral neck in patient who has no known risk factors such as prolonged, excessive physical activity or abnormal bone quality. The exact etiology of stress fracture of femoral neck is still not clear. We propose the relation between femoroacetabular impingement by excessive acetabular anteversion and coxa profunda and femoral neck stress fracture. Biomechanical effect by FAI mechanism in abnormal orientation of acetabulum and deep socket may predispose to development of stress fracture of femoral neck. Carpintero et al. [1] reported coxa vara, a form of cam impingement, is possibly related with stress fracture of femoral neck. There was a normal neck-shaft angle (128 in degree) and no abnormal head-neck offset in our case.

Stress fracture of femoral neck usually needs surgical treatment. Closed pinning method is known to be a gold standard treatment. But when its diagnosis is delayed or in displaced fracture, the complications after internal fixation such as avascular necrosis or nonunion can occur. If osteoarthritis was previously developed by FAI before stress fracture, hip symptoms can persist after fracture healing. When the stress fracture is associated with FAI, the combined cam or pincer lesion can be corrected with internal fixation by debridement of protruded head-neck junction and superior labrum [10]. We performed total hip arthroplasty because of combined hip osteoarthritis and the avoidance of nonunion by repeated abuttment.

We report a rare case of stress fracture of femoral neck in patient with excessive acetabular anteversion and overcoverage by coxa profunda which can support the hypothesis of role of FAI mechanism on development of stress fracture of femoral neck.

\section{References}

1. Carpintero P, Leon F, Zafra M, Serrano-Trenas JA, Roman M. Stress fractures of the femoral neck and coxa vara. Arch Orthop Trauma Surg. 2003;123(6):273-277.

2. Egol KA, Koval KJ, Kummer F, Frankel VH. Stress fractures of the femoral neck. Clin Orthop Relat Res. 1998;(348):72-78.

3. Muldoon MP, Padgett DE, Sweet DE, Deuster PA, Mack GR. Femoral neck stress fractures and metabolic bone disease. J Orthop Trauma. 2001;15(3):181-185.

4. Kuhn KM, Riccio AI, Saldua NS, Cassidy J. Acetabular retroversion in military recruits with femoral neck stress fractures. Clin Orthop Relat Res. 2010;468(3):846-851.

5. Korvala J, Hartikka H, Pihlajamaki H, Solovieva S, Ruohola JP, Sahi T, Barral S, et al. Genetic predisposition for femoral neck stress fractures in military conscripts. BMC Genet. 2010;11:95.

6. Ganz R, Leunig M, Leunig-Ganz K, Harris WH. The etiology of osteoarthritis of the hip: an integrated mechanical concept. Clin Orthop Relat Res. 2008;466(2):264-272.

7. Ganz R, Parvizi J, Beck M, Leunig M, Notzli H, Siebenrock KA. Femoroacetabular impingement: a cause for osteoarthritis of the hip. Clin Orthop Relat Res. 2003;(417):112-120.

8. Eijer H, Myers SR, Ganz R. Anterior femoroacetabular impingement after femoral neck fractures. J Orthop Trauma. 2001;15(7):475-481.

9. Beck M, Leunig M, Clarke E, Ganz R. Femoroacetabular impingement as a factor in the development of nonunion of the femoral neck: a report of three cases. J Orthop Trauma. 2004;18(7):425-430.

10. Taylor-Haas JA, Paterno MV, Shaffer MD. Femoral neck stress fracture and femoroacetabular impingement. J Orthop Sports Phys Ther. 2011;41(11):905. 